\title{
Family with an adolescent in the face of depression - possible effects in systemic family therapy
}

KEYWORDS

teenage depression, family, systems theory, adolescence, systemic family therapy

\begin{abstract}
The aim of this article is to describe the phenomenon of teenage depression in the context of the impact of depression on the functioning of the family system. The first part of the paper shows the understanding of the concept of the family on the basis of the system theory, paying special attention to the family life cycle and the function of symptoms in the family system. The second part of the article presents the etiology, symptoms and specificity of teenage depression. The developmental tasks characteristic for the age of adolescence were also reconstructed. The last part of the article is devoted to the ways in which depression can be understood from a systemic and family therapy perspective The possible ways and directions of working with a teenager and his parents are also indicated.

Adam Mickiewicz University Press, pp. 161-175

ISSN 2300-0422. DOI 10.14746/kse.2019.15.11

ORCID: https://orcid.org/0000-0003-3869-0900
\end{abstract}

\section{Introduction}

The family is changing together with the changing world - it is influenced by socio-cultural changes and historical events. Over the centuries, the problems faced by families have also changed, and families learnt how to respond to them in a developmental way. One of the areas that can and often generates crises in the family is the area of health and disease, especially in the case of the common, so-called, civilization diseases. The list of these diseases includes not only coronary heart disease 
and cancer, but also mental disorders, including depression. The Polish version of Google finds over 9 million results in response to the search of the word "depression". After entering the phrase "Do I suffer from", the first and fourth suggested answer is "Do I suffer from depression" and "Do I suffer from depression test". The word "depression" has entered the vocabulary used by Poles also thanks to subsequent social campaigns (for example, "Faces of depression", "Forum against depression", "Stop depression") or the establishment of 23 February as the National Day for Combating Depression by the Ministry of Health. This problem, which, according to estimates, affects several percent of the world's population (including about 1.5 million Poles), is increasingly discussed. However, adolescent depression has become a widely discussed issue relatively recently, and this coincides with the crisis in mental health care and changes in education. On the publishing market there are more and more books for parents of adolescents suffering from depression and books addressed to teenagers themselves. The issue is present in social media and is being taken up by public persons (vloggers and influencers, who are popular among young people, speak about teenager depression more and more often).

In this article I would like to present the phenomenon of teenage depression, especially in the context of the impact of depression on the functioning of the entire family system. The aim of this paper is to present depression from the systemic perspective and systemic family therapy. I also signal possible ways and directions of working with a teenager and his/her parents, as well as factors that may influence the emergence of depression. Therefore, in the first part of the paper, I refer to the definition of the family on the basis of the system theory and discuss the family life cycle which includes the tasks and processes characteristic for the development phase of a "family with an adolescent" that appear in the dynamics of the system. An important aspect is also the way in which we can understand the symptoms of depression - due to their importance and functions in the system.

\section{Definition of the family on the basis of the general systems theory}

The family can be defined on the basis of various disciplines, including psychology, sociology, pedagogy and law. With the development of the general systems theory, as a proposal for metatheory, systemic thinking has also begun to be used to understand the family. The general theory of systems was developed on the basis of constructivist philosophy. Constructivism in its basic assumption states that "no organism is capable of reflecting reality, but merely constructs an image of the world, a 'model 
that fits"' (Górniak, Józefik, 2003: 19). On the other hand, social constructivism assumes "that social reality is constructed and created primarily by discourse and joint actions. Cognition and knowledge arise within the framework of a specific culture, they are a product of that culture and its language" (Górniak, Józefik, 2003: 20). The application of the assumptions of the systems theory to the understanding of families was possible thanks to the work of G. Bateson. This anthropologist cooperated with researchers associated with e.g. the Institute in Palo Alto. The system as a concept derived from biology (works of Maturan and Varel) and cybernetics (works of L. von Bertalanffy) is understood as a set of elements that create something different than a simple sum of components. The system has a set of specific features, and its way of functioning is specific - it operates on the basis of feedback mechanisms, and in consequence, in system thinking, the principle of circular causality is adopted (moving away from traditional linear thinking). The systems are characterized by operational closeness, the existence of semipermeable borders which, while distinguishing the system from the background, allow it to exchange information with the environment, homeostasis, i.e. to strive for a balance that ensures stability and protects the system from disintegration. According to Maturan, systems are always autopoietic, that is, self-organizing and self-renewing. "Autonomy, self-regulation of the systems results in the fact that they are not subject to planned control from the outside, but they can react to disturbances and consequently change their state. This means that living organisms are subject to the laws that result from their structure and autopoietic organization" (Górniak, Józefik, 2003: 24).

From the perspective of the systemic theory, we can define a family as "a system with a specific structure, functioning patterns, relationship patterns, which, in order to last, must change. [...] The family is a psychosocial system, composed of individuals with biological conditions, which means that in describing it we must take into account all three levels: biological, individual and social" (Górniak, Józefik, 2003: 25). The family system is created by subsystems, i.e. individual family members who interact with each other and at the same time have their own unique point of view and individual way of experiencing the surrounding reality (including family reality). Thus, each person in the family influences the other, the state of one family member affects the state of other family members, but the ways of interpreting or understanding the situation differ between them. "Each structure is understood as a manifestation of the process it contains (e.g. the structure of a family in a systemic approach is a set of functional requirements addressed to its individual members)" (Janicka, Liberska, 2014: 8\%). Following Ludewig, we can assume that "all the behaviours that happen between people may be treated as feedback loops" (Ludewig, 1995: 14). Consequently, any behaviour of the people 
involved in interaction "influences the behaviour of the partner in interaction and is at the same time modified by the reactions of the partner. A linear model, in which behaviour is treated as a result of something, becomes useless" (de Barbaro 1999: 14).

To sum up: the system consists of a set of elements and mutual relations between them, which are dynamic and linked, the system constitutes a whole, is capable of functioning and a certain change. We always treat the system as a whole, and "the constituent objects and their attributes can only be understood from the point of view of their functioning in the system; the boundaries of the system are determined by its identity in time and space. Systems are open (flexible and partially permeable borders allow for exchange with the environment) and closed" (Janicka, Liberska, 2014: 7\%). From this perspective, we will think of family members as inextricably linked. Neither people nor their problems (or solutions to these problems) exist in a vacuum. "They are all intertwined in broader systems of interaction, the most basic of which is the family. The family is the primary and, except in rare cases, the most powerful system to which people belong" ( McGoldrick, Gerson, Shellenberger, 2007: 24-25). The family is never suspended in a vacuum - it functions in a specific social, economic and political context. It is surrounded by institutions, organisations and other families with whom it can interact. For a fuller understanding of the functioning of the family, but also of the individual within the family, it is necessary to consider all stressors affecting the family. These stressors may be variable in time and concern the reality both within the family and outside the family, i.e. within the community. Stressors include: historical events, the economic and political situation, institutions such as school, but also events such as illness or job loss (cf. McGoldrick, Gerson, Shellenberger, 2007: 26-29).

\section{Symptoms and their functions in systemic family therapy}

The adoption of systemic assumptions in the field of science about family has huge consequences in terms of understanding symptoms and disorders. First of all, this approach abandons the understanding of psychopathology exclusively as the intrapsychic reality of a human being, and from the individual level one needs to move to the system level - symptoms can be understood on the basis of their functions in the dynamics of the family system, which is usually related to maintaining balance within the system. "The basic assumption here is that the problems and symptoms reflect the adaptation of the system to its overall, current context at 
a given moment" (McGoldrick, Gerson, Shellenberger, 2007: 25). Actually, from the beginning of applying system thinking when working with the family, some of the concepts from the general theory of systems were used "to explain problem behaviours and psychopathological symptoms. The basic assumption of family therapy was that pathology, problems of one of the family members cannot be explained in terms of its disturbed intrapsychic processes, because they are an expression of dysfunctionality of the whole system. Symptoms could be used to maintain the status quo in the family or as a signal to change it. [...] By treating the family as a culture that produces its own stories and gives them meaning, it focuses rather on the way in which family members and the patients themselves define and give meaning to problems" (Górniak, Józefik, 2003: 26). It is recognised that all members who are more or less involved in the problem create a new system - the so-called problem system. Frequently, it is the problem-oriented system that allows the family to concentrate around the problem and unite in the fight against it. Thanks to this, the family system, even temporarily, is protected against disintegration. "It is therefore not surprising that families with children, especially during the period of adolescence, are the group to which family therapy is mainly addressed. It results from the assumptions of systemic thinking, i.e. the recognition that the behaviour of a given person is connected with the patterns of family relations, patterns of bonds and that - further on, through changes in the patterns of family relations and the meanings given to them - it is possible to cause a change in a given family member" (Józefik, 2014: 36).

\section{Family life cycle and characteristic developmental tasks}

Researchers observing the fate of subsequent families noticed that certain stages of family life are repetitive and of normative character - one stage determines and enables the occurrence of the next one. This phenomenon is called the family life cycle. The eight-phase model proposed by Duvall is considered classical. The eight consecutive phases form a coherent life story of a nuclear family, the beginning of which is the moment when two adults decide to bond and the end is marked by the death of both spouses. Starting from the first phase, i.e. marriage (without children), through the second phase, a family bringing up small children, then the following phases occur: third - a family with a child at preschool age, fourth a family with a child at school age, fifth - a family with adolescents, sixth - a family with children leaving home (i.e. the so-called empty nest stage) and finally the eighth, last phase of the cycle: aging parents (until the death of both parents) (cf. 
Namysłowska, 1997: 19, de Barbaro, 1999). Events of a biological nature (e.g. age of family members) and psychological nature (e.g. building a sense of autonomy) coincide with events of a formal nature (e.g. marriage).

We can see that the course of a nuclear family's life is quite similar - each of these phases presents its own challenges, but also a certain risk whether the system will survive. "It has been found that the family as a system develops and therefore changes with a simultaneous tendency to maintain balance. This quest for homeostasis helps the family to protect the system, to maintain its own identity. It has been described that the transition to each successive phase in the family life cycle can take place only when all the tasks of the previous phase have been completed. Otherwise, individual members of the family system may experience disorderly symptoms" (de Barbara, 1994: 19). Thus, the transition from one phase to another can be interpreted by the family (or the individual) as a crisis. If family members fail to find new, useful ways of coping, the symptoms (problems) and even the break-up of the system may occur. The family system striving for balance (homeostasis) will protect itself against disintegration. "The system is characterised primarily by a tendency to survive" (de Barbaro, 1994: 15). The concept of homeostasis is essential to understand the sustainability of the system. Satir sees the need to create the concept of family homeostasis in relation to the fact that "the family behaves as if it were an individual. [...] According to the concept of family homeostasis, the family acts in such a way as to achieve a balance in mutual relations. Family members help to maintain this balance in an open and hidden way. Repetitive, cyclical, predictable communication patterns show this balance. When family homeostasis is at risk, family members put a lot of effort in order to maintain it" (Satir, 2000: 17). Referring to the notion of family life cycle, according to which successive stages of family development are associated with a specific developmental crisis, the family must introduce changes in order to adapt to the changing circumstances. "The functionality of the family is assessed on the basis how family members cope with changes resulting both from the family's life cycle, i.e. its natural development processes, as well as from unforeseen random events (Górniak, Józefik, 2003: 25).

The key feature is the characteristic of the system, which assumes that any change in a certain part of the system (change of its element) affects the whole system (the other elements and the relations between them). The functioning of the system consists of two principles: equipotentiality and equifinality. The first means that the same causes can have different effects, the second means that even with different causes we can have the same effect (cf. de Barbara 1999: 11). The concepts of equipotentiality and equifinality are crucial in the interpretation of family dis- 
orders. The inability to identify a single cause makes it possible to relieve family members of a sense of guilt or taking on total responsibility - which, in the context of a family with a teenage child, is often one of the most important interventions that allows to start a therapeutic effect.

\section{A time of dynamic changes, i.e. a family with an adolescent}

From the point of view of this article, the fifth phase, i.e. a family with an adolescent child/children, is the most interesting. The most important tasks of this phase are the separation of a teenage child, where a successful separation is one that takes place without a sense of guilt. "This means that young people moving away from their families should be reassured that their parents will 'cope' without them. The example of this phase of the family life cycle clearly shows how all components of the system (subsystems) participate in what happens to the system as a whole. Parents should withdraw from the position of authority, and the borders around their subsystem should become much more flexible (open to the flow of information) than in families with younger children" (Namysłowska 1997: 22). The basic developmental task a teenager needs to fulfil is quite paradoxical: the quest for autonomy and separation is accompanied by the need to maintain a bond with the parents. In this phase, we observe a certain relaxation of boundaries within the family, which allows the teenager to move away and then to move towards to the family. This is the moment when young people gain the right to be independent and to experiment with their roles outside the family. "At the same time, the whole family system should become open to new values and ideas brought to it by young people, their friends, music" (Namysłowska 1997: 22). Especially the period of early adolescence may be a time of intense conflicts with parents, and the amount of time spent with them decreases. "However, some researchers stress that the process of creating identity, although often difficult and turbulent, does not necessarily mean that the relations between teenagers and their parents will drastically deteriorate" (Trempała, 2011: 277). If there are emotional bonds in the family, which allow for this relaxation (free moving away and getting closer), then this period does not necessarily need to be turbulent". According to Erikson, the solution to the growing conflicts between adolescents and adults is to introduce the principle of 'delegating authority'. It consists in a gradual increase of the participation of young people in their subjective decisions, while maintaining the right of the guardians to control those areas of life in which life experience is crucial" (Trempała, 2011: 278). 
A family with a teenager will go through a lot of changes. These changes affect not only the teenager him/herself, but also his/her siblings and parents. It is the parents who bear responsibility for and how this developmental crisis can be resolved. As always, the whole system is involved in events directly related to one family member. A strong desire to belong to the family stands in the way of achieving autonomy and independence - that is why it is important to help maintain ties with the family and develop new ways of their implementation. Literature emphasizes how important it is for a teenager to see that his/her parents also carry out tasks related to this phase of the family life cycle. These include preparation for the abandoned nest phase, i.e. parents' turning towards each other again - strengthening or rebuilding themselves as spouses, but also broadening their interests, participating in social life. Thanks to this "they show their daughter or son that they will be happy together when they are alone. On the other hand, parental misunderstandings, emotional divorce or a significant dysfunction or illness of one of the parents cause a dysfunction of the whole system, which may slow down or even prevent the process of gaining independence [...] because this phase carries a high risk of developing symptoms in one of the family members, most often the growing child. Their function will be to save the system from undertaking tasks that are too difficult at a given moment" (Namysłowska 1997: 22).

\section{The development of a teenager}

The adolescence period is above all a moment of many, often turbulent, changes both in the body and in the functioning of teenagers (mental and social functioning). A young person faced with the so-called developmental tasks, to some extent has to deal with them on his/her own. These tasks include the process of identity shaping - finding an answer to the question "who am I" and "what am I", moreover, "a confrontation of the previous image of oneself with reality [...], the acceptance of the changing appearance" (Miernik-Jaeschke, Namysłowska, 2016). The sexuality of teenagers is also developing, it is a moment of experimentation - of defining one's identity and sexual orientation. Changes in self-image are accompanied by a time when the teenager makes certain life choices and decides about his/her future - seeks a goal in life, develops passions and interests. There are also significant changes in the social context - there are new roles and the creation of closer, more lasting emotional relationships. The importance of the peer group and the willingness to belong to it also increases. Separation from parents is also crucial, as it increases the sense of autonomy, which gives more freedom, but also clashes with 
the sense of responsibility for oneself and one's own decisions, actions. This moment is important, but also difficult for the whole family system, as was mentioned earlier. As the authors emphasize, emotional separation from parents may involve a sense of fear and guilt towards them (cf. Miernik-Jaeschke, Namysłowska, 2016). The teenager must find his/her own way to cope with the challenges of this period. “The 'burden' of developmental tasks combined with hormonal changes occurring in the body during adolescence often results in: reduced or changeable mood, irritation, anxiety, low self-esteem, concentration on one's appearance, sometimes difficult behaviours (breaking social norms, auto-aggressive behaviours) - the socalled adolescent depression"1 (Miernik-Jaeschke, Namysłowska, 2016).

\section{Adolescent depression}

In the common sense, depression is associated with sadness, lack of willingness to act. Often, people do not treat depression as a disorder or illness, but rather as "having a worse day" or "being lazy". Therefore, there are many unfavourable myths about depression and people affected do not always seek help. "Depression is a condition characterized by long-lasting reduced mood and a number of other psychological and somatic symptoms. Depression, understood as a disease, belongs to the group of mood disorders. It can be chronic, with a constant intensity of symptoms, or it can take the form of recurrent episodes of mild, moderate or severe intensity, separated by periods of well-being. Depressive symptoms often accompany other mental disorders - e.g. anxiety disorders (in which case depressive-anxiety disorders are diagnosed) or are a reaction to unpleasant, traumatic events (adaptive disorders with the so-called depressive reaction)" (Miernik-Jaeschke, Namysłowska, 2016). Although depression is much more common, or diagnosed, in adults (currently we are talking about 350 million people worldwide and 1.5 million Poles who struggle with depression), it also affects children and young people. "Depression is diagnosed in 2\% of children (it affects girls and boys equally often) and even $8 \%$ of teenagers (girls more often). It is estimated that $20 \%$ of teenagers may develop depressive disorders understood in a broad sense, and some sources report that depressive symptoms are found in nearly one in three teenagers" (Miernik-Jaeschke, Namysłowska, 2016).

\footnotetext{
${ }^{1}$ Adolescent depression is: "a particular form of depression (some sources even say it is a normal stage of development). Although mental disorder classifications do not describe it as a separate disease, it is often used to refer to emotional and behavioural disorders observed in teenagers" (Miernik-Jaeschke, Namysłowska, 2016).
} 
In the case of adolescent depression, it is more likely that the cause of the disorder is multifactorial. There are three main groups of factors that can and often co-exist: biological, psychogenic and environmental. The first group includes genetic determinants - children from families with cases of depression have a greater chance of developing the disease, but also people with abnormal brain neurotransmitter activity or hormonal disorder. The second group includes, among others things, individual psychological construction, i.e. low self-esteem, lack of security, tendency to blame oneself, and moreover: "depressive thinking patterns (a tendency to automatically interpret facts and events to one's disadvantage), inability to cope with stressful situations, poor social skills" (Miernik-Jaeschke, Namysłowska, 2016). Finally, the third group of factors are the so-called "triggers", which may include: a difficult family situation (e.g. parents' divorce, experience of domestic violence), problems at school - learning problems and rejection by a peer group, as well as other difficult or traumatic experiences (e.g. sexual abuse). "Often symptoms of depressive disorders are revealed as a result of environmental and external factors, e.g. family conflict or school failure" (Miernik-Jaeschke, Namysłowska, 2016).

In order to diagnose depression, symptoms typical of depression must persist daily for at least two weeks. The symptoms of adolescent depression include: sadness, crying, but also, irritability, quarrelsomeness, unusual in the case of adults. Other symptoms may include withdrawal from social contacts, suicidal thoughts, auto-aggressive behaviour, reduced self-esteem, feeling discouraged or worthless, blaming oneself, the so-called resignation thoughts, depressive thinking. Teenagers often avoid activities that previously gave them joy, do not take up activities typical for them - this may be accompanied by a decrease or loss of a sense of joy, apathy. Depression is often accompanied by fear (unspecified, of constant intensity), a feeling of anxiety and inner tension appears. (cf. Miernik-Jaeschke, Namysłowska, 2016). "The authors [...] describe children’s depression by indicating the presence of typical symptoms observed in adult depression (sadness, anhedonia, decreased self-esteem, somatic symptoms). They also indicate the presence of symptoms, which are treated as typical for depression in children and/or adolescents. These symptoms include: withdrawal from social contacts, anxiety, aggressiveness, negativity, behavioural disorders, school absenteeism" (Role, 2001: 14). "Teenage depression" may be dominated by: "Anxiety, resignation, self-aggression, mood instability. Psychosocial factors play an important role in the dynamics of depression. Among them, the situation of families is very important. General social factors are also significant, as indicated above" (Rola, 2001: 17-18). 
The fact that depression is a syndromic disorder also makes it difficult to notice it. "This means that in its clinical picture there may be other, additional, individual symptoms, such as behavioural disorders, difficulties in school, somatic symptoms" (Role, 2001: 5). These symptoms are often treated as symptoms of the so-called "period of rebellion" or an ordinary reluctance of a child to learn. "The presence of these and other symptoms in its clinical picture has a fundamental influence on the cognitive, emotional and social functioning of children with diagnosed depression" (Role, 2001: 5). School failure exposes children to even greater stress and anxiety and may increase their fear of school or discourage them from learning (there may be a thought that it is not worth trying if you do not see the results). There are many typologies of depression (see Role, 2001), and these considerations go far beyond the size of this work. Nevertheless, it is worth quoting the classification by McConville, Boag and Purohit (after Role, 2001), in which the authors distinguish three types of depressive disorders, while stressing that they are "directly related to the level of development achieved by the child" (Role, 2001: 15). These include: "The affective type, which according to the authors is typical for younger children, aged 6-8. The axis symptoms include: sadness, a sense of helplessness, a sense of hopelessness; the cognitive type - where the main symptom of depression is reduced self-esteem and frequently occurring suicidal thoughts. This type of depression, according to the authors, has been observed in children over the age of 8 ; and depression accompanied by a feeling of guilt, which concerns only children over the age of 11" (Role, 2001: 14). Another classification can be found in Kępiński, who distinguishes four basic clinical forms of adolescent depression, i.e. the apathetic-abulic form, rebellious form, resigned form, and labile form (cf. Rola, 2001: 16). On the other hand, Bomba distinguished four psychopathological syndromes of depression in adolescents: "Pure depression, which is typical of decreased mood, weakening psychomotor drive, undefined fear of the future; depression with resignation, where the symptoms of pure depression are accompanied by: failure in learning, a feeling of a lack of sense of life, suicidal thoughts, tendencies and attempts; depression with anxiety is expressed by mood changes and self-destructive behavioural disorders occurring against the background of pure depression; hypochondriac depression includes symptoms of pure depression and somatic manifestations of anxiety and hypochondriac concentration on the body" (Role, 2001: 17). According to Bomba, depression in youth may occur as a consequence of difficulties in implementing the developmental tasks envisaged for this period. 


\section{Teenage depression - the systemic perspective}

The disease undoubtedly makes it difficult, and often impossible, to carry out development tasks. This also applies to depression which affects teenagers. In the course of this disorder, people have difficulties in fulfilling compulsory schooling, and their learning outcomes clearly deteriorate. Depression has a negative impact on their relationships with peers. The adolescence period should be a moment when the teenager performs successive roles related to life within a peer group, while at the same time separating from the family, which is effectively prevented by depression. It also has a significant impact on family relationships. In this context, we can notice a kind of regression - a teenage child is usually independent in many areas, parents no longer have to watch him or her or control him or her in the context of clothing, hygiene, sleep or school. Also the relationship between parents and the child changes - it is a time when we move from a diagonal, hierarchical relationship to a partnership relationship that will soon be beneficial for the adult child of the parents. Depression interferes with this process. In the course of depression there is a disturbance of the daily rhythm, difficulties with learning - it is the parents who have to take responsibility for the basic functioning of the child and help him/her. They must increase control. As shown earlier, the occurrence of problems, especially in the case of children, can cause a great sense of guilt, affecting both the parents and the patients themselves. Unfortunately, there exist many harmful stereotypes concerning depression, and people affected often hear that they should take care of themselves, try harder or motivate themselves. Such a conviction also functions "in the minds" of people with depression, which intensifies their feeling of guilt. That is why it is so important to psycho-educate the whole family about depression and to show that it is a disease, and not someone's bad will or intentional action. The metaphor of a cold or a broken leg is very useful at this point, as it allows to illustrate and separate the problem from the person affected by it.

From the point of view of the system theory (or in broader terms, in accordance with the assumptions of constructivism), we may say that depression is a kind of label, a name, and not a real existence. However, such a label can be very useful, especially at the beginning of providing help. First of all, it brings a sense of relief and removes responsibility. It also makes us realize that the teenager "did not invent" his or her symptoms, and his or her experiences have already been described (and considered as real). It can reduce the overwhelming sense of loneliness in the face of problems. The word disease also takes away the feeling of guilt - after all we say that a disease does not choose its victim - which allows to take away the bur- 
den of responsibility from the patient. Of course, there is a certain risk in this kind of thinking. It may cause a feeling of lack of influence and effectively discourage people from taking any actions that could help or bring relief. Restoring the sense of empowerment will be another important therapeutic effect, and the teenager's belief in his/her abilities and their influence on their own life should be strengthened. For this purpose, the technique of externalisation is also used, i.e. an intervention which, at the linguistic level, makes it possible to separate the problem (symptom) from the person himself. This helps to realize that a person suffering from depression is not just the disease, and the disorder has not dominated his or her life - teenagers and their families often say that their life begins to revolve around the disease - by concentrating on the problem they stop functioning outside it, or they get the impression that their whole life is reduced to the disease.

An important issue in working with a family with an adolescent is the issue of the adolescent growing up and becoming independent. "Working to strengthen the processes of separation/individuality can also be a challenge for those parents who fear their child's attempts to become independent and their willingness to make their own decisions" (Józefik, 2014:40). Depressive symptoms can have a protective function - by preventing the separation process, they protect parents from experiencing anxiety. Therefore, it would be important to strengthen the parents so that they are ready to accept the child's independence.

Adolescent depression is also seen as a threat due to learning and schooling difficulties. School absenteeism increases the backlog and increase learning difficulties. "This example illustrates a more general issue, which is often the case in the therapy for families with teenagers, namely time pressure. The mental and emotional problems of adolescents need to be solved quickly enough not to hinder them from carrying out their developmental tasks. When this does not happen, we observe a snowball effect" (Josephine, 2014: 42). Time pressure is felt primarily by parents who watch their child "suffering from depression", while the world does not slow down even for a moment. It is worth sensitizing parents to their own hierarchy of values - is school success more important than mental health? In addition, it is important to talk about the temporal nature of the illness and the possibility of building a vision for the future.

Depression, like other children's and adolescents' disorders, can also have a stabilising effect on a parental relationship at risk of disintegration. The emergence of problems requires parents to seek help and focus on their child. This is another argument in favour of strengthening parents in their role, but it also shows how important it is to relieve the teenager from the sense of responsibility for parents and family - of course, a large part of these processes are subconscious and 
take place on a circular basis. Therefore, it is important to avoid looking for those guilty, or rather to see "the complex context of family life and other co-existing risk factors" (Josephine, 2014: 36). In this sense, it is important to involve not only the young people affected by depression, but also the parents (the family system) in the process of treatment and recovery from depression.

\section{Conclusion}

The way out of depression is not easy both for the teenager and his/her family. It requires a lot of sacrifice, patience and perseverance. The first and most important step is to notice the problem and seek help. As I stressed above, the key issue in the context of depression seems to be psycho-education - showing the family that depression is a disease, secondly, that there are a number of activities that can help the child, and that the supporting presence of parents is very important. Often the teenager does not actively seek contact with the parents by him/herself and, especially at the beginning, does not declare that he or she needs the support or the presence of parents. The responsibility for actively seeking contact with the child and organising time spent together lies with the adults. One of the paradoxes of depression may be the fact that at the end of the road the family underwent from diagnosis to cure, there may be positive changes in family relationships. In a family that has experienced adolescent depression, the ties are often closer, more authentic than the initial ones. Such a family experiences more understanding, warmth and openness.

\section{Bibliography}

Amroziak Konrad, Kołakowski Artur, Siwek Klaudia, Nastolatek a depresja. Praktyczny poradnik dla rodziców i młodzieży, GWP, Sopot 2018.

de Barbaro Bogdan (red), Wprowadzenie do systemowego rozumienia rodziny, Wydawnictwo Uniwersytetu Jagiellońskiego, Krakow 1999.

Górniak Lech, Józefik Barbara (ed.), Ewolucja myślenia systemowego w terapii rodzin. OD metafory cybernetycznej do dialogu i narracji, Wydawnictwo Uniwersytetu Jagiellońskiego, Krakow 2003.

Harwas-Napierała Barbara i Trempała Janusz (ed.) Psychologia rozwoju człowieka. Rozwój funkcji psychicznych, Vol. II, Wydawnictwo Naukowe PWN, Warsaw 2002.

Janicka Iwona, Liberska Hanna, Psychologia rodziny, PWN Warsaw 2014.

Józefik Barbara, Terapia rodzin nastolatków - dylematy, kontrowersje, [in:] Psychoterapia 3 (170) 2014. 
Ludewig Kurt, Terapia systemowa. Podstawy teoretyczne i praktyka, transl. by M. Ubertowska, GWP, Gdańsk 1995.

McGoldrick, Monica; Gerson, Randy; Shellenberger, Sylvia, Genogramy. Rozpoznanie i interwencja, transl. by Hartman Monika, Wydawnictwo Zysk i S-ka, Warsaw 2007.

Miernik-Jaeschke Magdalena, Namysłowska Irena, Zaburzenia depresyjne u dzieci i młodzieży, Medycyna Praktyczna 2016 [accessed online 20.02.2019] https://www.mp.pl/pacjent/pediatria/ choroby/psychiatria/81302,zaburzenia-depresyjne-u-dzieci-i-mlodziezy

1Namysłowska Irena, Terapia rodzin, PWN, Warsaw 1997.

Parkinson Monika, Reynolds Shirley, Depresja u nastolatka. Poradnik dla rodziców, transl. by Grażyna Chami, Wydawnictwo Rebis, Poznań 2018.

Rola Jarosław, Depresja u dzieci, Wydawnictwo Akademii Pedagogiki Specjalnej, Warsaw 2001.

Satir Virginia, Terapia rodzin. Teoria i praktyka, transl. by Olena Waśkiewicz, GWP, Gdańsk 2000.

Trempała Janusz (ed.) Psychologia rozwoju człowieka. Podręcznik akademicki, PWN, Warsaw 2011. 
